\title{
NOVO ENFOQUE SOBRE LIDERANÇA CENTRADA NA VIDA
}

\author{
Prof. José A. Bonilla (UFMG) \\ E-mail : bonilla.bhz@terra.com.br
}

\begin{abstract}
Resumo
Neste artigo discute-se a importância da introdução da dimensão espiritual na agenda organizacional. Isto não significa introdução de religião, e sim do significado e sentido da vida humana, tanto a nível pessoal como organizacional.

Um aspecto básico dentro dessa dimensão espiritual é o conceito de integridade, definido como "ter a coragem e a auto-disciplina para viver segundo nossa verdade interior". É o papel do gerente transmitir essa integridade para seus funcionários.

Conclui-se que é necessário introduzir a dimensão espiritual na vida organizacional. Ela representa o princípio integrativo que precisa equilibrar o outro princípio (oposto mas complementar), o auto-afirmativo, hoje prevalecente, que se preocupa só com a prosperidade das partes. O futuro pertencerá às organizações que possam sintonizar a visão de conjunto com os aspectos específicos.
\end{abstract}

Palavras chaves: Liderança Organizacional, Dimensão Espiritual, Integridade.

\section{Summary:}

This article discusses the importance of the introduction of the spiritual dimension in the organizational agenda. This does not mean an introduction of religion, but the introduction of meaning and matter of human life at both personal and organizational levels.

A basic aspect within this spiritual dimension is the concept of integrity, quoted as "being courageous and self-controlled to live according to our inner truth". It is a managerial role to pass on this integrity to their subordinates.

Therefore, it is necessary to introduce the spiritual dimension into organizational life. It represents the integrative principle, that is needed to balance with the other principle i.e., the selfaffirmative (opposite but complementary). This one prevails today and considers just the prosperity of the independent parts. The future will be of organizations that are able to integrate the vision of the whole with specific aspects.

Key words: Organizational Leadership, Spiritual Dimension, Integrity. 


\section{NOVO ENFOQUE SOBRE LIDERANÇA CENTRADA NA VIDA}

\section{Introdução}

Na primeira metade do século XVII e graças ao talento e genialidade de alguns pioneiros como Bacon, Descartes e Galileu, o método científico, impregnado de racionalidade, irrompeu no seio da sociedade humana, sobrepujando uma visão dogmática, obscurantista, antihumana e pseudoespiritual, representada pela Inquisição. Reformas e contrarreformas religiosas, aparecimento de novas Igrejas, seitas ou grupos específicos, têm povoado nosso planeta, especialmente durante o século XX.

O método científico, praticado no início por cientistas idealistas, que só procuravam aumentar o conhecimento, pouco a pouco começou a ser dominado por instituições poderosas (Universidades, Academias de Ciências, Institutos de Pesquisa, Empresas Privadas). Em muitos casos houve resultados benéficos para o gênero humano (novos remédios, meios mais rápidos de transporte e comunicação em geral, novas máquinas que levou a reduzir os esforços humanos na execução de certos trabalhos, etc.). Mas, simultaneamente, foram criados novos meios de poluição, destruição e devastação do meio ambiente, bombas atômicas e mísseis intercontinentais, exclusão de pessoas, perigosa alteração climática do planeta, etc.

Ou seja, a ambigüidade parece ser a conseqüência mais evidente desta situação. Uma pergunta indiscreta, neste entorno, pode ser feita: quem financia a pesquisa científica? É claro que quem a financia sente-se no direito de marcar sua orientação, deixando para os cientistas o modo de operar, mas não o poder de escolha. É por isso que o método científico, a grande esperança da Humanidade, a partir de sua criação não cumpriu todas as expectativas, porque o uso do mesmo não foi explicitado. E esse uso não é assunto científico; é problema ético.

Nesse marco referencial, chegamos ao século XXI. As descobertas da Física subatômica (teoria da relatividade, teoria quântica, a recente teoria da complexidade) mostram um mundo totalmente diferente àquele que era percebido em séculos anteriores. Agora a ciência mais atualizada converge para a espiritualidade (Capra 1982,1984).

Einstein (1981) afirmou: "Não considero automaticamente um homem de ciência aquele que só sabe manejar instrumentos e métodos julgados científicos. Penso somente naqueles cujo espírito se revela verdadeiramente científico". Ainda ele acrescenta: "O espírito científico, fortemente armado com seu método, não existe sem a religiosidade cósmica”.

Mas que religiosidade cósmica é essa? Ele mesmo responde: “A religiosidade do "sábio consiste em espantar-se, em extasiar-se diante da harmonia das leis da Natureza, revelando uma inteligência tão superior, que todos pensamentos humanos nem todo seu engenho podem desvendar, diante dela a não ser seu nada irrisório”.

Independente do conteúdo, a última frase de Einstein encerra uma grande lição moral: o maior cientista de todos os tempos reverencia humildemente a "harmonia das leis da Natureza", obviamente não criadas pelo homem. Entretanto, alguns cientistas de estrutura média ou até baixa, se destacam por sua arrogância.

Será então a dimensão espiritual, uma nova dimensão que deveremos considerar, tanto a nível pessoal como organizacional, ou será apenas um sonho evanescente? Talvez esta dúvida 
possa ser esclarecida, consultando as recomendações da máxima autoridade mundial sobre Educação, a Unesco. Veja-se:

“O conhecimento científico, através de seu próprio movimento interno chegou aos confins onde pode começar o diálogo com outras formas de conhecimento. Nesse sentido, reconhecendo as diferenças fundamentais entre a ciência e a tradição espiritual, constatamos não a sua oposição, mas sim sua complementaridade”.

Declaração de Veneza (1986).

“A Educação Superior deve empreender a transformação e a renovação mais radicais que jamais tenha enfrentado, de forma que a sociedade contemporânea, que vive atualmente uma crise profunda de valores, possa transcender as considerações meramente econômicas e assumir dimensões éticas e espirituais mais arraigadas”.

Conferência Mundial sobre Educação Superior (1998).

\section{Conceitos básicos}

Se estudarmos as questões que os gerentes são obrigados a enfrentar hoje em dia, mais profundos se tornam os temas. Não se trata apenas de planejamento das atividades técnicas, das vendas, do atendimento do cliente, etc. Cada vez fica mais claro que é necessário mergulhar nas grandes questões da vida humana, envolvendo basicamente seu significado e seu sentido. Perguntas chaves são: "o que faço na vida tem algum valor (fora de aumentar os lucros de meu patrão)?”, “como poderia ter uma vida mais valiosa no trabalho e fora dele?”, "vivo de acordo a meus valores?" "tenho, mesmo, valores específicos, ou simplesmente me adapto aos valores alheios, porque eles são convenientes para manter e aumentar meu nível de vida?” "nível de vida e qualidade de vida são a mesma coisa?”, "vale a pena lutar pelos nossos valores, ou somos tão insignificantes que é melhor nos deixar arrastar pela correnteza enquanto ela nos seja favorável?”

Essas e muitas outras perguntas e especialmente suas respostas, mostram-se hoje altamente preocupantes. A anestesia generalizada que prevalece em nossa sociedade, começa a estar ameaçada pela multidão de mudanças e efeitos até agora não percebidos. A teoria da complexidade com suas energias dissipativas, atratores estranhos, ordem e desordem, autopoiese, etc. (ver Oliveira, 2000) abre caminhos anteriormente não previstos, afetando definitivamente a nossa visão da sociedade e da Natureza.

Nesse marco referencial, precisamos utilizar todos os recursos que o ser humano possui e não apenas os físicos e mentais que até agora comandam a vanguarda do conhecimento. Os aspectos emocionais e espirituais precisam agora ser reconhecidos e aproveitados para o bem comum (Ver Barrett 1988, cap. 2). À inteligência emocional proposta por Goleman (1990), segue-se a inteligência espiritual (Zohar e Marshall, 2000; Wolman, 2001), cuja base física acaba de ser descoberta por Singer (1992), Persinger (1993), Llinas e Ribary (1993), Deacon (1997) e outros. Trata-se de um novo tipo de conexão neural, chamada de unitiva, que completaria as outras conexões já conhecidas: serial (intelectual) e associativa (emocional).

Espiritualidade e religião são palavras que muitas vezes são confundidas, mas pode existir espiritualidade sem religião, assim como religião sem espiritualidade. Também podem ir juntas.. Hawley (1995) propôs essa tarefa a uma turma de brilhantes alunos de Mestrado numa Universidade indiana e o resultado (ligeiramente alterado pelo autor, para uma maior clareza), foi o seguinte: 


\begin{tabular}{|c|c|}
\hline Religião & Espiritualidade \\
\hline - Produto de um determinado tempo e local & - O objetivo, e não o caminho \\
\hline - Destinado a grupos (ou povos) & - Destinada a pessoas individuais \\
\hline $\begin{array}{l}\text { - Concentra-se mais no caminho (códigos } \\
\text { de conduta) que no objetivo }\end{array}$ & $\begin{array}{l}\text { - } \begin{array}{l}\text { Contem elementos comuns a todas } \\
\text { religiões }\end{array} \\
\end{array}$ \\
\hline - Um sistema de pensamento & $\begin{array}{l}\text { - Uma aventura em direção a nossa origem } \\
\text { individual }\end{array}$ \\
\hline $\begin{array}{l}\text { Um conjunto de crenças, rituais e } \\
\text { cerimônias destinado a ajudar no } \\
\text { progresso ao longo do caminho }\end{array}$ & $\begin{array}{l}\text { - Um estado, além dos sentidos (inclusive } \\
\text { do pensamento) }\end{array}$ \\
\hline - Instituições e organizações & - Investigação em direção ao Eu interior \\
\hline $\begin{array}{l}\text { - Uma comunidade para compartilhar os } \\
\text { fardos e as alegrias da vida }\end{array}$ & $\begin{array}{ll}\text { - } & \text { A transição da incerteza para a clareza } \\
\text { (um modo de vida pessoal) }\end{array}$ \\
\hline
\end{tabular}

Hawley não menciona o que seria realmente o objetivo. Mas o significado último de espiritualidade é entrar em contato direto com as Energias Superiores, O Criador ou Deus, segundo cada um queira denominar a Fonte de onde emanou tudo (e portanto nós).

Cornelssen (1986) já nos adverte que atualmente as pessoas serão "chamadas a encarar o além que existe dentro delas, sem sacerdotes, igrejas ou cerimônias, simplesmente dentro de sua própria natureza, totalmente sós”.

Precisamos lembrar um conceito espiritual básico: tudo o que precisamos está dentro de nós. Ou seja, não precisamos nos tornar alguma coisa: empresários bem sucedidos, trabalhadores satisfeitos ou professores destacados. Mas para encontrar dentro de nós esse "todo", temos que nos aprimorar na disciplina mais abrangente que existe: a Espiritualidade.

É claro que não estamos propondo voar trás de experiências aéreas e desprovidas de valor. A Espiritualidade, para ser plena, precisa estar relacionada com as coisas muito concretas e tangíveis: trabalho, relações humanas, sobrevivência física etc. Neste artigo, a ênfase será dada a relação entre a Espiritualidade e as Organizações.

\section{A nova agenda organizacional}

Hawley (1995) começa a desenvolver este tema com uma citação de Studs Terkel: “A maioria de nós tem ocupações que são pequenas demais para nossos espíritos”.

É impressionante a força e o ensinamento transmitido por essa idéia! Não importa que sejamos faxineiros (obrigados a fazer um trabalho estressante e rotineiro) ou magnatas das finanças (com milhões de dólares em nossas mãos). Uns e outros, estamos mais ou menos intensamente esmagados, por um sistema que nos impinge modelos falsos de vida (o famoso "american way of life”), valores desumanos (o lucro acima de tudo), o desejo compulsivo, e muitas vezes irracional de possuir produtos (e o sofrimento psicossomático associado quando não podemos comprá-los) etc etc 
Por isso é que nossas ocupações acabam sendo pequenas demais para o nosso espírito. Ele quer, na verdade, utilizar nosso corpo e nossas capacidades intelectuais para devolver - com amor e consciência - à Humanidade uma parcela (por menor que seja) de contribuição construtiva. É o nosso espírito que pode transformar o sentimento do trabalho como um castigo, no sentido de trabalho como dever social, independente que sejamos, como foi falado, faxineiros ou magnatas... ou professores universitários.

Hawley (1995) vai mais longe quando afirma: “as questões fundamentais para os gerentes e líderes contemporâneos, não são mais de tarefa e estrutura e sim de espírito!”

Ele esclarece que as questões atuais que integram a agenda administrativa, tais como produtividade, custos, lucros, organizações, assim como o lado humano, deverão continuar sendo desenvolvidas, mas agora deve ser feito um acréscimo fundamental: "Vamos direto às questões verdadeiras da vida. Vamos ao significado e ao propósito, e mais além, aos sentimentos de vazio, e à nossa verdadeira experiência de vida”.

A nova agenda administrativa, segundo aquele autor, tem quatro componentes: corpo (bem estar no local de trabalho); mente (o alicerce intelectual sobre o qual o empreendimento é construído), coração (os aspectos humanos), mas também...espírito. O espírito, segundo Hawley tem a ver com "fome de objetivo, significado e identidade. Temos fome de um contato mais rico com a vida; ansiamos pela experiência de uma "vida" plena, vibrante, enquanto nos encontramos neste planeta. Temos fome de compreender quem somos e como nos encaixamos neste todo. É como se todo o tempo que passamos sem respostas, tivesse feito com que a fome crescesse”.

E aqui voltamos para o passado. O futuro não pode ser grandioso e nem sequer digno, se esquecermos o que os homens mais desenvolvidos nos têm ensinado. Até o iconoclasta Nietzsche reconhece a prevalência do espírito. E lá estão Jesus, Buda, Paulo, Platão, Hermes Trismegisto, Aquenaton, e os modernos Luther King, Gandhi, Madre Tereza e o Dalai Lama, entre outros.

Que feitiço feito pelos adoradores do bezerro de ouro, pode - no Terceiro Milênio continuar adormecendo as consciências humanas e deslumbrá-las como crianças, cujos olhos brilham pelo papel pintado e pelos brinquedos dinâmicos?

É o feitiço do comodismo gratificante (todos os dias temos coisas “novas” para comprar), da superficialidade (para que pensar, se o sistema pensa por nós?), do derrotismo ("nada posso fazer para mudar as coisas”). Mas na medida em que a conscientização humana avança, o feitiço tende a se dissolver.

Entretanto, para que essa dissolução aconteça, precisamos penetrar no cerne da vida moderna: as organizações. E qual é o tremendo desafio da nova agenda administrativa? Nada mais e nada menos que introduzir o espírito no mundo dos negócios. No lugar de credos desumanos, que só beneficiam uns poucos em prejuízo de muitos, precisamos introduzir nas organizações, credos que forneçam significado.

Hawley (1995) acrescenta que devemos enfrentar questões retiradas da agenda do Espírito: "Quem somos nós?; O que estamos realmente fazendo aqui?; Qual é o nosso objetivo, nosso chamado, nossa visão de grandeza? Qual é a coisa maior do que nós, e da qual fazemos parte?”... "No centro desse novo credo está o tema de envolvimento contínuo, não somente por parte dos empregados, mas também dos fornecedores e dos clientes” (Claro que está subentendido o papel crucial dos gerentes). 
Ou seja, às ondas geradas na década de 90: Gestão da Qualidade Total (Bonilla 1993, 1994) e das Organizações de Aprendizagem (Senge 1990, 1995), segue-se na agenda administrativa, a entrada do fator Espírito, já na primeira década do Século XXI.

Uma das idéias fundamentais de Hawley é que: "podemos, e precisamos ser espírito e corpo, simultaneamente". Isto é o cerne da abordagem holística, que no limiar do Terceiro Milênio vem em auxílio do cartesianismo, que não conseguia perceber que esses dois componentes - a diferentes níveis energéticos, ou a diferentes intensidades de freqüências vibratórias coexistem, sendo opostos sim, mas simultaneamente, complementares.

Niels Böhr, o genial físico danés, já colocou este último conceito há mais de 70 anos, o que lhe valeu o Prêmio Nobel. Mas lamentavelmente, a maioria das Ciências, entre elas as Administrativas, desconsidera (ou ignora, ou rejeita) o princípio da complementaridade e continuam amarradas aos conhecimentos sobre o mundo físico que Newton arredondou há quase 300 anos!

Assagioli (1971) define o drama central da Humanidade como “a necessidade de fusão de nossa personalidade com nosso Eu Interior”. Mas isso é, em todo caso, uma redescoberta, pois há milênios os sábios reunidos em locais inexpugnáveis, como as Pirâmides, conheciam isto como o credo básico de qualquer religião. Entretanto, muitas delas, penetradas pela ambição e ignorância de pseudo-espiritualistas que assaltaram as posições de poder, como Torquemada, levaram a muitas pessoas lúcidas (entre elas Marx: “a religião é o ópio dos povos”), a descrer, como São Tomé de coisas que não podem perceber com seus recursos sensoriais.

De qualquer forma, no seio de uma sociedade desesperançada, sem valores, sem fé, sem rumo e exausta, aquele drama central tende a explodir. E as organizações são produtos dos homens. Se quisermos melhorá-las, precisamos ir ao âmago, ao resgate da essência do ser humano. É por isso que a Espiritualidade precisa ter, entre outros lugares, um lugar bem visível na nova agenda administrativa.

Acrescenta Hawley (1995): “A consciência espiritual permanente, é nada menos que um novo estado mental para a maioria das pessoas. É um novo modo de ser, um modo de vida mais completo, um modelo de vida que ajuda a trazer de volta a totalidade pela qual elas anseiam. É a idéia central da nova agenda administrativa”.

Vaill (1989), observando durante mais de uma década empresas bem sucedidas, diz que "sistemas de alto desempenho referem-se constantemente ao espírito sentido pelas pessoas. A dimensão espiritual está sempre envolvida em situações de grande realização”.

Peters (1987), por sua vez, informa que os programas de qualidade que funcionam, são “quase místicos”.

Relata Hawley que quando o Dalai Lama ganhou o Prêmio Nobel da Paz, a pergunta feita com maior freqüência pelos magnatas da indústria presentes, foi: "Como podemos introduzir mais ética e espiritualidade em nossos negócios e nossa vida cotidiana?” E a resposta do sábio tibetano foi: "Faça isso com o coração, dentro de sua própria cultura”.

A frase do Dalai Lama, encerra um exemplo maravilhoso: ele apesar de ser o líder de uma das religiões mais importantes do mundo, o budismo, não "receita” religião, e sim convoca o Espírito que existe dentro de cada um de nós. 


\section{O princípio integrativo no trabalho e na vida}

Hawley (1995) afirma: “no novo calendário administrativo a reverência é o ingrediente que todo mundo ama, mas não consegue definir. É o adorável molho secreto. É o que dá sabor, coração ao cozido”... “A reverência é a força que empurra o novo paradigma administrativo”.

Mas: reverência?... Que significa? Ajoelhar-se frente ao Papa, ao Dalai Lama, à alguma imagem reconhecida como sagrada? Hawley responde: "Não. Reverência consiste em dedicação, animação e entusiasmo. Nela há um respeito profundo e uma admiração profunda”... “A reverência é um estado de comprometimento intensificado"... "Essa reverência deve ser desenvolvida para quatro itens: missão, produtos, clientes e empregados" (Acreditamos que Hawley esqueceu a comunidade; por causa disto a poluição ambiental avança devastadoramente).

Mas essa reverência, precisa de um alicerce, e Hawley não hesita em apresentá-lo: ele o chama de Amor!

Mas, amor e resultados empresariais combinam? Na verdade, os executivos se ocupam e preocupam com as partes frias e duras de seus cargos, tais como tomar decisões difíceis, fazer cumprir normas, demitir milhares de pessoas... Portanto, uma atitude amorosa, algo cálido e suave, pode esvaecer aquela força objetiva que os mantém em suas posições. Acaso, aquelas atitudes "viris" não são aquelas que os transformaram em "tigres”? E não foi para exercitá-las que foram contratados (e assim ganhar polpudos salários)? Que proposta maluca é essa?

Na verdade Hawley (1995), que é um verdadeiro herege do final do século XX, (e que teria sido incinerado na fogueira da Inquisição se vivesse na Idade Média) está resgatando essa extraordinária palavra (amor), que desde que foi pronunciada pelo Mestre há 2000 anos não cessou de ser deturpada.

Já tivemos dificuldades pessoais pela utilização dessa palavra, e geralmente preferimos utilizar um sinônimo, que por se tratar de uma expressão nova, não foi ainda contaminada: princípio integrativo. Para melhor explicar seu significado, devemos dizer que o paradigma holístico está apoiado em dois princípios básicos: o auto-afirmativo, que promove a expansão, o crescimento das partes, e o integrativo que se preocupa com o conjunto, com o contexto, com a Unidade.

Desta forma, o princípio auto-afirmativo é fundamental para que uma pessoa, uma comunidade ou uma empresa, se desenvolvam adequadamente dentro de seus respectivos marcos referenciais, expandindo suas biodiversidades específicas. Mas, se estas biodiversidades ficam soltas, elas estão expostas a serem atraídas por forças obscuras oriundas da imperfeição humana, de modo que a expectativa de contribuições autênticas para a melhoria da Humanidade acaba (como o documenta claramente o atual estágio da sociedade humana), se transformando em uma grande frustração daquelas.

Precisa-se então, mergulhar no oposto complementar: o princípio integrativo (ou amor, para aquele que preferir). O princípio integrativo é a argamassa que permite que o edifício físico se mantenha; é o raio que ilumina a mente para um trabalho construtivo e positivo; é o sopro da vida que faz palpitar os nossos corações.

E é ele que deve ser incorporado nas empresas do Século XXI. Esse será o grande salto qualitativo, que os gestores precisam impulsionar. 
Hawley (1995), apresenta essa idéia de forma ligeiramente diferente, segundo a biodiversidade de seu estilo: "Trabalhar bem através de outras pessoas exige cooperação, trabalho de equipe, lealdade, compreensão, tolerância, auxílio, unidade e amizade. Exige confiança, envolvimento, ajuda, permissão e delegação. E o que são essas coisas? Não são apenas os elementos essenciais para a eficácia do trabalho: são qualidades do amor. $O$ amor não é somente belo: é imperativo!"

Ainda acrescenta: “O amor no trabalho está além da suavidade e da gentileza. Inclui o fato das pessoas se respeitarem e se importarem com as outras, de ajudarem, de protegerem a dignidade das outras. Essas são qualidades amorosas em ação"... "Deixe de lado a idéia de que o amor tem de ser suave. O verdadeiro amor pode ser duro ou suave (Lembremos que Jesus, quando necessário foi duro, como quando açoitou os vendilhões no templo. Uma importante figura contemporânea, disse: "Hay que endurecerse, pero sin perder la ternura jamás”).

Ainda um pouco mais: “Não podemos culpar o trabalho pela falta de amor. O problema não é que os papéis profissionais careçam de amor; na verdade, são neutros. As pessoas é que representam seus papéis de um modo não-amoroso. É uma questão do cenário que criamos, e dentro do qual representamos nossa vida. Ele é feito de amor ou de medo”. (Ou seja, de princípio integrativo combinado adequadamente com o auto-afirmativo, ou de princípio auto-afirmativo, solto e exacerbado).

Eis a questão: integrar ou desintegrar. O "management” americano optou pela segunda alternativa e a impingiu para os outros países, especialmente os do Terceiro Mundo.

Para restabelecer o princípio integrativo nas pessoas, nas empresas, nas comunidades e nas nações, precisamos ir ao centro, ao cerne de nosso ser. E que encontraremos?: lá está esperando o Espírito, no linguajar de Hawley, ou quem sabe, dito de forma mais simples: o nosso Eu Interior, aquele que é uma faísca da Energia Suprema.

A Sabedoria Milenar (ou Espiritualidade) sempre disse a mesma coisa: a grande tarefa do ser humano é se reencontrar com esse escondido ser interior. É por isso que estamos no planeta Terra. Quando consigamos vislumbrar esse encontro, com certeza nos serão fornecidas ferramentas hoje inimagináveis, para lapidar a sociedade humana em forma coerente com o seu destino, quais sejam - pelo efeito da conscientização individual - compreender que somos separados (neste nível tridimensional), e gotas de níveis sucessivamente mais altos (Humanidade, Terra, Sistema Solar, Universo físico, O Criador).

O grande desafio é passar da compreensão intelectual desses conceitos, para sua vivência afetiva e depois voltar para o mundo tridimensional, através da ação.

É por isso que a dimensão espiritual precisa ser introduzida nos curricula universitários, e daí passar para as organizações. 


\section{A integridade pessoal e empresarial}

Hawley (1995), que é o inspirador deste artigo diz: “O caráter é o elemento que distingue, a essência, o ingrediente básico do novo paradigma administrativo. Ele pode dar à vida da empresa um calor e uma especialidade, que hoje em dia estão muito comprometidos. As pessoas têm fome de caráter”...

... "A palavra caráter refere-se a um conjunto de idéias e virtudes sociais interligadas, dentro das quais estão a moralidade, a ética, a honestidade e os valores humanos. No trabalho administrativo o caráter consiste em integridade”.

“O caráter é o ingrediente fundamental que provoca a singularidade e a totalidade da vida. A falta de caráter é uma deficiência, uma falta de vitamina $C$, necessária à vida. Quer ou não, as pessoas verbalizem isso, ou pensem nisso, elas sabem que a ausência de caráter significa que são menos do que eram, menos do que deveriam ser e menos do que se destinavam a ser”.

Aqui entramos num assunto fundamental. Hawley cita suas reuniões com altos executivos americanos "triunfadores" e "bem sucedidos”. Perguntados sobre caráter no local de trabalho eles respondem coisas como:

- “Cobiça é o nome da música de hoje em dia! Cobiça por dinheiro, poder, status, ou que seja. Será que nunca vai acabar? Quanto mais dinheiro eles - bem, nós - fazemos, mais queremos. Todo mundo está fazendo isso, e se você não fazer, vai parecer idiota”.

- "É o padrão: pegar, pegar, pegar. Depois de algum tempo se torna uma segunda natureza. Dar? Você nem pensa nisso. Só pega, pega. Simplesmente nem pensa a respeito".

- Enfrente os fatos: você precisa ganhar a vida, e para isso precisamos estar numa empresa; e para estar numa empresa sem se autodestruir, você precisa se comprometer (com ela e não com seus sentimentos).

- "Sua integridade pessoal é jogada fora. Você raspa uma camada de princípios a cada dia, para poder viver, e raspa mais, no dia seguinte. Triste, mas verdadeiro, amigo. Depois de algum tempo você pára de pensar nisso e o entorpecimento... ajuda”.

Em meia página está retratado o caráter da maioria dos executivos americanos (e dos países como Brasil), que seguem cegamente aquele modelo de “management”.

É que nos sugere esse retrato? Uma triste confissão de falta de caráter. O ser humano se preza de ser um ser racional e autoconsciente. Mas o que esses executivos dizem é tudo ao contrário, pegam um caminho pré-definido e depois não conseguem parar. Tornam-se (eles também), escravos do sistema. A única diferença que eles exibem com a maioria das outras pessoas, é que têm o bolso cheio de dinheiro. Mas, o que interessa, o que é essencial, a vida foi esvaziada. Por isso "o entorpecimento ajuda”.

Mas isso não é irracional? A autoconsciência não fica anestesiada... ou quem sabe amputada? E esses são os líderes que conduzem o mundo! Para onde? Com certeza para o abismo. Vamos reagir a isso ou vamos acompanhá-los?

Há uma velha história que diz : "se você tiver que escolher entre um cavalo veloz e um cavalo lento, qual preferiria?” Os cavaleiros antigos e os executivos de hoje respondem ao 


\section{Revista Eletrônica de Ciência Administrativa (RECADM) - ISSN 1677-7387 \\ Faculdade Cenecista de Campo Largo - Coordenação do Curso de Administração \\ v. 3, n. 1, maio/2004 - http://revistas.facecla.com.br/index.php/recadm/}

uníssono: “o cavalo veloz.” Mas os sábios antigos (e os modernos) fazem outra escolha: “aquele cavalo que estiver indo no rumo certo!"

Acrescenta Hawley (1995): “Integridade é ter a coragem e a autodisciplina para viver segundo sua verdade interior”. Deve-se lembrar que a integridade não é um atributo apenas individual e sim coletivo. "Cada empresa também deve seguir seu coração coletivo e sua alma coletiva".

Coração coletivo? Alma coletiva? Que conceitos são esses? Toda empresa tem um coração e uma alma. Na maioria delas, o coração está corrompido, e a alma presa numa gaiola. O sistema, muito inteligente, nos oprime e nos gratifica simultaneamente. Nos oprime, conduzindo-nos ao caminho rápido da gratificação (consumismo exacerbado, devastador e muitas vezes absurdo). Parece como que estamos no melhor dos mundos, e que seria um ato de idiotice extrema querer mudá-lo.

Mas isso é fachada, verniz, máscara. As pessoas sofrem, porque foi esvaziada sua integridade, e colocada em seu lugar casca brilhante e colorida, que pode ser simbolizada pelo "jingle": "tudo vá melhor com Coca-Cola".

Porém, já está passada a hora de recuperar essa integridade. E quem deve tomar a iniciativa? Os deserdados, os excluídos, os famintos? Não. Quem deve assumir a responsabilidade são os administradores das organizações, aqueles que detêm o poder. O desejo deles de ocupar cargos mais altos pode ser aceito em termos de crescimento de sua biodiversidade (princípio autoafirmativo), mas precisam envolver o princípio integrativo, complementar. E este princípio implica em aumento de sua responsabilidade. É o gerente que deve trazer o poder do caráter e a vitalidade da integridade para a organização. Só ele pode fazê-lo.

Mas, como os gerentes podem estimular a integridade? Hawley (1995) responde: "primeiro precisamos modelar a integridade pessoal, e em seguida exigi-la aos subordinados” ... "O gerente (de qualquer nível) precisa estabelecer seus próprios valores e viver impecavelmente a partir deles, e fazer isso abertamente, para que os outros e imitem”... "Mande sinais nítidos de cima. O chefe deve fazer o pronunciamento".

Um exemplo desse credo é fornecido por Autry (1991) a seus subordinados dos grupos Meredith Corporation: "Seremos justos, sensíveis, com os clientes, com os fornecedores e com a comunidade em geral. Obedeceremos todas as leis, de fato e em espírito, e faremos sempre a coisa certa, em todas as situações, no máximo de nossa capacidade. E se fracassarmos, faremos todo o necessário para consertar”.

Evidentemente, ser claro sobre valores e regras éticas não é difícil a nível conceitual, mas as coisas podem ser complicar a nível operacional. Disse Srivatsva (1998): “integridade é um evento interativo”. Portanto o diálogo, é a grande ferramenta capaz de conduzirmos à integridade coletiva.

Hawley (1995) é ainda mais específico: “As pessoas precisam de um fórum de discussão sobre os dilemas da integridade no trabalho. Precisam de um lugar onde possam falar sobre suas questões específicas com relação à integridade. A ausência de um fórum assim é causa do desgaste moral sentido pelas pessoas nas empresas"... "Os gerentes precisam criar a ocasião para esses fóruns, que não deverão constituir um programa formal, e sim, conversas informais sobre caráter, ou como eventos para diálogos morais”. 
Eis que está chegando o momento da queda das máscaras. Os credos da maioria das empresas são muito bons, éticos e até espiritualizados. Mas a aplicação deles é, geralmente, muito falha. Se a empresa não vai viver de acordo com seu credo, é melhor que o faça pedaços. Pelo menos, isso significará um primeiro passo em direção à integridade.

Hawley (1995) define com maestria o que seria o gerente líder: "Sua tarefa é nada menos que conferir integridade (a seus subordinados)” ... “A recaracterização de um sistema humano não é simplesmente um "modo de operar"; é uma atitude, um clima, um jeito de ser. Baseia-se no conhecimento interno do que é certo e bom, e confiar nesse conhecimento intuitivo”.

E continua: "Você dota seu pessoal de coração e coragem para viver com integridade. Você literalmente os encoraja. Você proporciona o destemor, a totalidade e a bondade"... "Tudo isto está além do trabalho comum do gerente: é a administração espiritual. É aqui que o mago que há em você começa a atuar. É você, o gerente-líder, que precisa guiar a viagem até o coração interior. Você é que traz esse poder. É você que acende esta lâmpada”.

Ficamos arrepiados ao ler isso! Mas não é por aí que poderemos encontrar uma saída do túnel tenebroso no qual estamos engaiolados? Ela só poderá ser guiada por o Novo Gerente líder, o Gerente do Terceiro Milênio!

O que funcionou durante a primeira metade do século XX em termos de boa administração, foi se esvaindo na medida em que o século avançava, até estar à beira do colapso na década do 70, quando o "milagre japonês", centrado no cliente e preocupado com o crescimento dos funcionários, produziu severos estragos na indústria americana, especialmente automotriz.

Os EUA importaram o modelo japonês de Qualidade Total, mas não compreenderam sua essência, apesar de que os criadores eram oriundos daquele país (Deming, Juran). Não podiam fazêlo, pelo simples motivo de que a filosofia daquele lhe era alheia. O autoritarismo, elitismo e imediatismo, tão próprios do "management" americano, não tinham como ser substituídos pela gerência participativa, a delegação de funções e a visão em longo prazo. Mas os líderes continuaram pensando apenas numa coisa: “faturar”.

Depois vieram as novas "descobertas" e "genialidades", como a reengenharia, o “downsizing”, o “empowerment” e as megafusões. A conseqüência é que o capital continua se acumulando, e os excluídos também.

Com esse pesado fardo de um "management” anacrônico, mas apresentado como o único válido, entramos no século XXI. A era dos simples administradores acabou; agora está nascendo a era dos gerentes-líderes. Mas que líderes são esses?

Hawley (1995) detalha, basicamente seis atributos do Novo Gerente. Eles são: criador do sentido, servidor, guia, difusor de paz interior, otimismo e guerreiro (dármico ${ }^{(*)}$ ).

É muita coisa para desenvolver nos novos gerentes de modo a transformá-los em verdadeiros líderes? É possível; mas isso não faz mais que potencializar a necessidade irreversível que a Universidade tem, de abandonar os estereótipos técnicos, científicos e filosóficos que nos amarram ao nefasto modelo gerencial prevalecente.

\footnotetext{
${ }^{(*)}$ Guerreiro “dármico” significa um lutador por causas justas, nobres, construtivas. Não se trata de Átila e seus hunos; talvez possa ser representado por São Jorge, lutando contra o Dragão.
} 
Precisamos é um gerenciamento próprio do século XXI, impregnado de preocupação pelo significado e sentido da vida humana. Isto implica incorporar a dimensão espiritual na agenda organizacional.

\section{Conclusões}

A dimensão espiritual tem sido praticamente ignorada, tanto pela Universidade como pelas organizações. Entretanto, a evolução cada vez mais complexa da sociedade humana nos obriga a utilizar todos os recursos disponíveis para que essa evolução seja a favor do ser humano, e não apenas a favor de determinados grupos poderosos, como acontece atualmente.

A introdução da dimensão espiritual na agenda educacional já foi recomendada pela Unesco (1986, 1998). Na área organizacional, cada vez mais autores (Hawley, 1995; Barrett, 1998; Zohar e Marshall, 2000; Wolman, 2001) salientam a imperiosa necessidade de incorporar aquela dimensão na agenda gerencial.

Essa dimensão espiritual (diferente de religião ou religiosidade), envolve "fome de objetivo, significado e identidade”, tanto pessoal como organizacional. Ou seja, precisa-se introduzir o "espírito" no mundo dos negócios. Cada vez fica mais evidente nas organizações, que quando se produzem situações com alto nível de realização, a dimensão espiritual está presente. Isto é simples de compreender: nós, seres humanos não somos apenas corpos físicos ou parafusos, nem também seres vivos pouco desenvolvidos. Somo seres altamente complexos que temos, é verdade, um corpo físico , assim como um raciocínio potencialmente muito poderoso. Mas também temos vida afetiva e vida espiritual. No enfoque holístico isto é denominado de princípio integrativo (que há 2000 anos o Mestre proclamou na forma de uma singela palavra de quatro letras: amor, hoje bastante deturpada).

Esse princípio integrativo (Capra,1984), precisa equilibrar o princípio atualmente prevalecente, o chamado auto-afirmativo, preocupado com a prosperidade das partes (pessoas, organizações, nações). Já o integrativo cuida do coletivo, do conjunto , do todo.

Portanto, o principal ingrediente a ser adicionado ao novo gerente, próprio do século XXI, o gerente líder, é a integridade, e ela não pode ser desenvolvida, se não darmos atenção especial ao significado e ao sentido da vida humana (a nossa e a das demais pessoas). E essa atenção nos conduz necessariamente à dimensão espiritual , tanto a nível de pessoa como de organização.

\section{Bibliografia}

- $\quad$ ASSAGIOLI, R. The act of will. Nova Iorque: Penguim. 1971

- $\quad$ AUTRY, J. Love and profit. Nova Iorque: Morrow, 1991.

- BARRETT, R. Libertando a Alma da Empresa. São Paulo: Cultrix. 1998, 192 p.

- BOnIlla, J. A. Resposta à Crise: Qualidade Total Autêntica em Bens e Serviços. São Paulo: Makron Books. 1993, 238 p.

- BOnilla, J. A. Qualidade Total na Agricultura: Fundamentos e Aplicações. Belo Horizonte: Secretaria de Agricultura. 1994, 344 p. 
- BONILLA, J. A. Abordagem holística. Belo Horizonte: CAD/FACE/UFMG. 2001, 52 p.

- $\quad$ CAPRA, F. O Ponto de Mutação. São Paulo: Cultrix. 1982, 427 p.

- CAPRA, F. O Tao da Física. São Paulo: Cultrix. 1984, 332 p.

- $\quad$ CORNELSSEN, L. Hunting the intelligence. Tiruvanmalai: Centenary Publications. 1996.

- $\quad$ DEACON, R. The Symbolic Species. Londres: The Pinguim Press. 1997.

- $\quad$ EINSTEIN, A. Como vejo o mundo. Rio de Janeiro: Nova Fronteira. 1981, 213 p.

- GOLEMAN, D. Inteligência Emocional. Rio de Janeiro: Objetiva. 1995, 370 p.

- HAWLEY, J. Redespertar espiritual no Trabalho. Rio de Janeiro: Record, 1995, 250 p.

- LlinAS, R. e ROBARY, U. Coherent 40 Hz-Oscilation Characterizes Dream States in Humans. Proceedings National Academy of Sciences (USA) 90:2078-81. mar. 1993.

- OliVeirA, M. Caos, Emoção e Cultura. Belo Horizonte: Ophicina da Arte e Prosa. 2000, $152 \mathrm{p}$.

- PERSINGER, M. A. Religious and Mystical Experiences as Artefacts of Temporal Lobe Function. Nova Iorque: Random House. 1993.

- PETERS, T. Thinking on chaos: Handbook for a Management revolution. Nova Iorque: Knop. 1987.

- SENGE, P. A Quinta Disciplina. São Paulo: Best-Seller. 1990, 352 p.

- SENGE, P. La Quinta Disciplina em la Práctica. Barcelona: Granica. 1995, 593 p.

- $\quad$ SIEGER, B. S. Love, Medicine and Miracles. Nova Iorque: Harper e Row. 1986, 325 p.

- UNESCO. Declaração de Veneza. 1986.

- UNESCO. Declaración Mundial sobre Educación Superior en el Siglo XXI: Visión y Acción. Conferencia Mundial sobre Educación Superior. Paris, outubro 1998, 10 p. Disponível em <http://habitantes.elsitio.com/burente/conferencia> Acesso em 15.jul.2001.

- VAILL, P. Managing as a performing art. São Francisco: Jossey-Bass. 1989.

- WOLMAN, R. Inteligência Espiritual. São Paulo: Ediouro. 2001, 336 p.

- ZOHAR, D e I. MARSHALL. Inteligência Espiritual. Rio de Janeiro: Record. 2000, 340 p. 